\title{
Fever of unknown origin in special groups
}

\author{
(D) Leonardo Fernandes e Santana ${ }^{1}$ \\ (iD) Mateus de Sousa Rodrigues ${ }^{1}$ \\ (iD) Marylice Pâmela de Araújo Silva² \\ (D) Rodrigo José Videres Cordeiro de Brito ${ }^{3}$ \\ (iD) Jandir Mendonça Nicacio ${ }^{4}$ \\ Dita Marina Soares de Castro Duarte \\ (iD) Orlando Vieira Gomes ${ }^{6}$
}

\begin{abstract}
1. Discente de Medicina na Universidade Federal do Vale do São Francisco (UNIVASF), Petrolina, PE, Brasil 2. Médica formada pela UNIVASF, Petrolina, PE, Brasil 3. Médico Infectologista. Professor MSC efetivo da disciplina de Infectologia da UNIVASF, Petrolina, PE, Brasil 4. Médico Hematologista. Preceptor da Residência Médica de Clínica Médica do Hospital Universitário da Unifasf. Professor efetivo das disciplinas de Doenças hematológicas e de Oncologia da UNIVASF, Petrolina, PE, Brasil 5. Médica Reumatologista. Preceptora da Residência Médica de Clínica Médica do Hospital Universitário da UNIVASF. Professora efetiva da disciplina de Reumatologia da UNIVASF, Petrolina, PE, Brasil 6. Médico Nefrologista. Preceptor da Residência Médica de Clínica Médica do Hospital Universitário da UNIVASF. Professor MSC efetivo da disciplina de Medicina de Urgência da UNIVASF, Petrolina, PE, Brasil
\end{abstract}

\section{SUMMARY}

Fever of undetermined origin (FUO) is a challenging entity with a striking presence in hospitals around the world. It is defined as temperature $\geq 37.8^{\circ} \mathrm{C}$ on several occasions, lasting $\geq$ three weeks, in the absence of diagnosis after three days of hospital investigation or 3 outpatient visits. The main etiologies are infectious, neoplastic, and non-infectious inflammatory diseases. The diagnosis is based on the detailed clinical history and physical examination of these patients, in order to direct the specific complementary tests to be performed in each case. The initial diagnostic approach of the FUO patient should include non-specific complementary exams. Empirical therapy is not recommended (with few exceptions) in patients with prolonged fever, as it may disguise and delay the diagnosis and conduct to treat the specific etiology. The prognosis encompasses mortality of $12-35 \%$, varying according to the baseline etiology.

KEYWORDS: Fever of Unknown Origin. Fever. Child. Neutropenia. Aged. HIV.

\section{INTRODUCTION}

Fever of unknown origin (FUO) is a clinical entity that is highly prevalent worldwide and affects all age groups, with some peculiarities at extreme ages and in special groups. ${ }^{1-4}$ Most of the times, it is associated with infectious, neoplastic, and rheumatological etiologies. A meticulous clinical examination is still the foundation for approaching patients with prolonged fever, despite a large number of diagnostic resources. ${ }^{5.6}$ Empirical therapy is performed only in selected cases, as the diagnosis of the underlying disease may be delayed in these cases. ${ }^{7.8}$
The objective of this study is to review the different presentations of fever of unknown origin in special groups of patients (children, neutropenic, elderly, HIV+, and hospitalized patients).

\section{METHODS}

This is a literature review carried out on the more recent publications found in the PubMed Central ${ }^{\circledR}$ (PMC) and SciELO ${ }^{\circledR}$ databases. On PMC, the search used the descriptor "Fever of Unknown Origin" and 
the secondary descriptors: "Analysis", "Complications", "Diagnosis", “Enzymology”, "Epidemiology”, "Etiology", "Immunology", "Metabolism", "Microbiology", "Mortality", "Parasitology", "Pathology", "Physiology", "Physiopathology", "Statistics and numerical data", "Therapy", "Virology". All secondary descriptors were associated with the main descriptor using the tool "OR". A total of 3,736 results were found. Then, the following filters were applied: "Review”, "Clinical Trial”, "Meta-Analysis", "Systematic Reviews", "Full text”, "published in the last 5 years", and "Humans". After applying the filters, the results were narrowed down to 75 items. Of these, 21 articles were selected after an analysis of their summary and abstract. On Scielo, the descriptor "Febre de origem indeterminada" was used, retrieving a total of 15 matches, which were reduced to 13 after the filters "Brasil" and "Ciências da Saúde" were applied. We did not use any filter for year of publication while selecting Brazilian articles due to the scarce scientific production/update on the subject. After analyzing the papers, three were selected based on the scope of the present study, totaling 24 references.

\section{DISCUSSION}

Fever of undetermined origin was initially characterized in 1961 by Petersdorf and Beeson as a record of oral temperature $>38.3^{\circ} \mathrm{C}$ on at least three different occasions, for a minimum of three weeks, in the absence of diagnostic hypotheses that could explain the fever after a week of investigation., ${ }^{17-11}$ Since this is a condition of singular characteristics, there are still divergences among some authors regarding its exact concept. One of the most accepted concepts of classical FUO encompasses axillary temperature $\geq 37.8{ }^{\circ} \mathrm{C}$ on several occasions, for a period $\geq$ three weeks, with no diagnosis after three days of hospital investigation or three outpatient consultations. ${ }^{2.12}$

There are more than 200 possible causes for FUO; the main ones are infectious, neoplastic, and rheumatic. ${ }^{1.13}$ Despite all the clinical, laboratory and imaging resources, $7-50 \%$ of cases can remain with no diagnosis (idiopathic). ${ }^{114-19}$ In developed countries, neoplastic and rheumatic causes are usually predominant, while in developing countries infections often prevail. ${ }^{1}$

Some groups of patients require a special approach because they present a FUO profile with specific peculiarities in relation to the classic pattern. They are neutropenic, hospitalized (nosocomial FUO), HIV positive, elderly patients and children..$^{11,13,20-24}$

\section{FUO IN PEOPLE LIVING WITH HIV/AIDS (PLWHA)}

The definition FUO associated to HIV requires confirmed HIV infection, fever $\geq 37.8^{\circ} \mathrm{C}$ in several occasions, duration $\geq$ four weeks (outpatient) or $\geq 3$ days in hospitalized patients, with no diagnosis after three days, despite adequate investigation (including at least 48 hours of microbiological culture). ${ }^{2.14}$ A study conducted in Brasil between 1989 and 1997 recorded all cases of FUO in HIV positive patients at a general hospital of Minas Gerais. ${ }^{3}$ Figure 1 shows the causes of FUO identified in the study patients. During this period, there were 55 cases of FUO associated with HIV. The specific etiology was defined in $81.8 \%$ of the cases (45 patients), of which $74.5 \%$ (41 patients) had infectious causes of FUO. Tuberculosis was the most frequent etiology (43.9\%), with extrapulmonary involvement in 16 of 18 cases. Pneumocystosis, diagnosed in six patients, was the second most frequent etiology (14.6\%), followed by Mycobacterium avium infection, which was found in five patients (12.5\%). Cryptococcal meningitis and non-Hodgkin lymphoma were diagnosed in three patients (each) and together were the fourth most common FUO etiologies in PLWHA (7.3\% each). Coinfections by salmonellosis/ schistosomiasis, sinusitis and histoplasmosis were recorded in two patients (4.9\% each). Neurosyphilis,

FIGURE 1. CAUSES OF FUO ASSOCIATED WITH HIV IN A STUDY CONDUCTED IN BRASIL (1989-1997), ON 55 PATIENTS ${ }^{3}$.

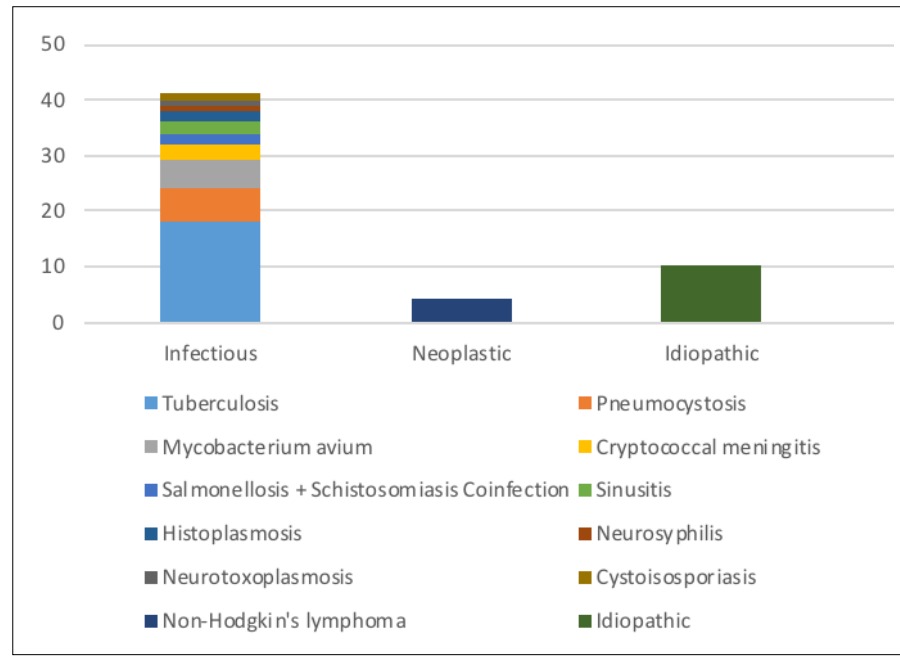

Adapted from Lambertucci JR, Rayes AAM, Nunes F, Landazuri-Palacios JE, Nobre V. Fever of undetermined origin in patients with the acquired immunodeficiency syndrome in Brasil: report on 55 cases. 
neurotoxoplasmosis, and cystoisosporiasis were diagnosed in one patient (2.4\% each). Idiopathic FUO was found in 10 patients $(18.2 \%)$. The more effective diagnostic procedures were biopsies (lymph node, liver, bone marrow), analysis of the cerebrospinal fluid, complete blood count, the purified protein derivative (PPD), computed tomography (CT), and parasitological stool test. ${ }^{3}$

The acute phase of an HIV infection may also present itself as a mononucleosis-like syndrome (rash, fever, lymphadenopathy), being a possible etiology of FUO. ${ }^{13}$ For some authors, cytomegalovirus can be responsible for up to 5\% of FUO cases in PLWHA. It is the most common viral infection associated with HIV. It has an opportunistic behavior and is reactivated when the CD4+ T serum lymphocytes are in levels $<100 / \mathrm{mm}^{3} .^{13}$ Fever associated with the use of antiretroviral drugs should be investigated, especially when other causes of FUO have been eliminated. ${ }^{13}$

\section{FUO IN NEUTROPENIC PATIENTS}

The definition of FUO in neutropenic patients requires neutrophils $<500 / \mathrm{mm}^{3}$, fever $\geq 37.8{ }^{\circ} \mathrm{C}$ on several occasions, and no diagnosis after three days, in spite of adequate investigation (including at least 48 hours of microbiological culture). ${ }^{2}$ Neutropenic patients present greater vulnerability to the development of infections. The peculiar approach to this group of patients is centered around the shortest in-

FIGURE 2. FACTORS OF WORSE PROGNOSIS IN NEUTROPENIC PATIENTS WITH FUO

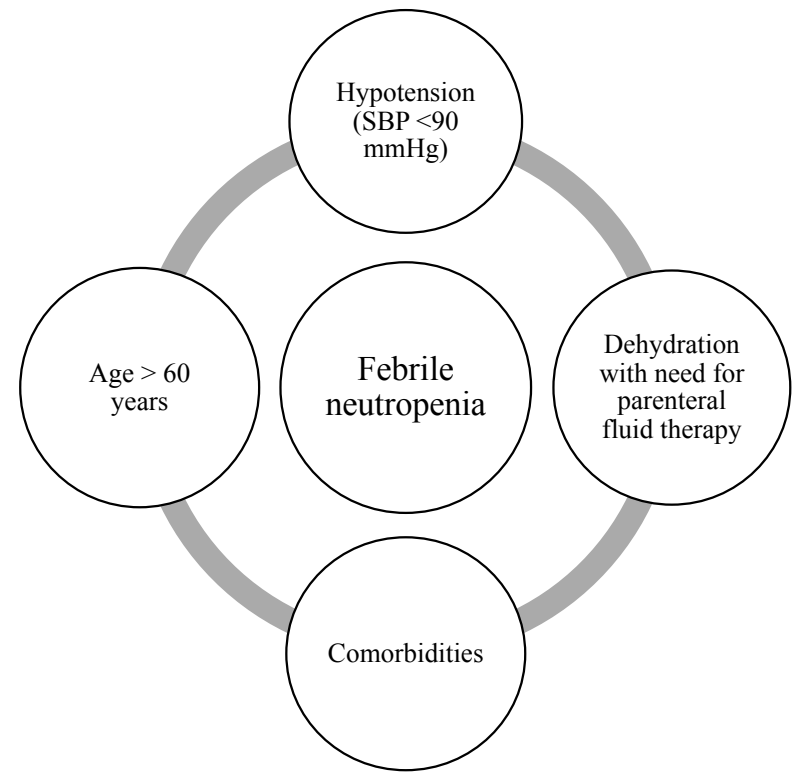

terval between diagnosis and the beginning of therapy since infections can progress with high morbidity and mortality in febrile neutropenic patients when there is no appropriate antimicrobial therapy..$^{15}$ Thus, once the fever has been identified, antibiotic therapy should be initiated immediately, empirically, until the results of the microbiological cultures are available. ${ }^{15} \mathrm{It}$ is worth noting that the empirical treatment will remain in cases in which no specific focus or infectious agent is identified..$^{15}$

The main pathogens in these patients are Staphylococcus aureus, Streptococcus spp., Enterococci, coagulase-negative Staphylococci, gram-negative bacilli, and Pseudomonas aeruginosa. ${ }^{15} \mathrm{~A}$ study carried out by the European Organization for Research and Treatment of Cancer (EORTC) reported that it is possible to isolate an infectious agent in febrile neutropenic patients in only $43 \%$ of the cases (22\% of which are bacteremia). ${ }^{14}$ However, $78 \%$ of the patients responded to the empirical antimicrobial treatment, reinforcing the idea that there are occult bacterial infections that can cause FUO in neutropenic patients. ${ }^{14}$

The risk of complications varies according to several factors such as: age, nadir and duration of the neutropenia, presence of hypotension, presence of comorbidities, and dehydration. ${ }^{8}$ Age greater than 60 years, presence of hypotension (systolic blood pressure $<90 \mathrm{mmHg}$ ), presence of comorbidities (eg. chronic obstructive pulmonary disease), dehydration with the need for parenteral fluid therapy (which increases the risk of hospital infection associated with the catheters) are factors that indicate a worse prognosis (Figure 2). ${ }^{8}$ Empirical treatment with antifungal agents should be considered in some cases. ${ }^{14}$

\section{FUO IN CHILDREN AND ADOLESCENTS (0-18 YEARS)}

FUO in patients younger than 19 years old has the same diagnostic definition used in adults, only the age of the patients affected differs. In general, few studies are performed with a focus on children and adolescents, perhaps because there is not so much discrepancy around the natural history of the disease among pediatric and adult groups, in addition to the diagnostic approach consisting in a broad clinical, laboratory, and imaging examinations, as mentioned. However, there are some literature reviews in this context that are noteworthy.

Approximately $20 \%$ of pediatric emergencies of 
children between 2 and 24 months are caused by fever, and in $20 \%$ of these patients, no initial etiological diagnosis is reached..$^{13.14}$ The patient's age is an important factor in the evaluation of FUO. In children aged $<6$ years, respiratory infections, urinary tract infections (UTI), and juvenile idiopathic arthritis (JIA) are more prevalent. ${ }^{11}$ Tuberculosis, inflammatory bowel disease, and lymphomas are more common in adolescents. ${ }^{11}$ Antipyretic therapy is recommended in the following situations: bad overall condition of the child, very high fever $\left(>40{ }^{\circ} \mathrm{C}\right)$, presence of comorbidities that increase the metabolic demand (congenital cardiopulmonary diseases, for example), and in cases of dehydration.

The infectious etiology is also the most frequent in children. ${ }^{14.20}$ The greatest difficulties for the correct etiological derive from the inexpressive symptomatology that is common in this age group. Urinary tract infections are the most prevalent bacterial infections in children and represent $5-7 \%$ of FUO cases in this group. ${ }^{6,7,17}$ The likelihood of UTI as a cause of FUO depends on the presence of risk factors such as: temperature of at least $39^{\circ} \mathrm{C}$, fever for more than one day, age $<12$ months, Caucasian ethnicity, in addition to the absence of another infectious focus. ${ }^{14}$ Infectious endocarditis in the pediatric population commonly presents itself without alterations in cardiac auscultation, so the diagnosis should be confirmed by laboratory findings and imaging. Abscesses are also possible diagnoses in cases of a previous history of surgeries (mainly abdominal). ${ }^{6}$ The prevalence of occult bacteremia (OB) went from $2.4-11.6 \%$ to $0.17-0.36 \%$, thanks to the advent of vaccines against Haemophilus influenzae type $b$ and pneumococcus, but it should still be investigated as a cause of FUO in children. Currently, its main agent is Escherichia coli (56\%), followed by group B Streptococcus (21\%), and Staphylococcus aureus (8\%). ${ }^{7}$ Rhinosinusitis, tooth infections, brucellosis, leptospirosis, systemic mycoses, visceral leishmaniasis, and osteomyelitis are described as potential etiologies of FUO. ${ }^{6.11}$ Continuous or relapsing fever patterns with oscillations below $1^{\circ} \mathrm{C}$ can be the first sign of typhoid fever. ${ }^{6}$ Viral infections can cause FUO in children, and its main etiologic agents are the herpes virus, adenovirus, enterovirus, and the cytomegalovirus. ${ }^{6,13,18}$

Non-infectious inflammatory diseases that cause FUO in children and adolescents are represented mainly by JIA and systemic lupus erithematosus
(SLE) (together, can account for more than 90\% of the cases). ${ }^{11}$ Synovitis with high $\left(39-40{ }^{\circ} \mathrm{C}\right)$ and intermittent fever with one or two daily peaks in individuals aged $<16$ years may suggest JIA, especially when associated with a evanescent maculopapular rash, generalized lymphadenopathy, hepatosplenomegaly, serositis, in the absence of infectious and tumor causes. SLE is a FUO etiology, even if fever is not a diagnostic criteria of the disease, it usually accompanies the intense systemic involvement. It is more common in female children. Vasculitis are important causes of FUO in children, particularly Kawasaki disease in children younger than one year of age. ${ }^{6}$

The main neoplasms associated with FUO in children and adolescents are leukemias and lymphomas. Hematological neoplasms should always be suspected in cases of hemorrhages, paleness, hepatosplenomegaly, lymph node enlargement, weight loss, and bone pain associated with fever (Figure 3). The natural history of Hodgkin lymphoma may start with B symptoms, such as weight loss of $>10 \%$ of body weight, night sweats, pruritus, in addition to the periodic fever, known as the Pel-Ebstein fever (peaks that exceed $40^{\circ} \mathrm{C}$ with a periodicity of 7-10 days). The differential diagnosis involves entities that mimic this type of neoplasia, such as Castleman disease (idiopathic and lymphoproliferative disease), and Kikuchi-Fujimoto lymphadenitis (histiocytic necrotizing lymphadenitis), both of which can cause FUO in children. ${ }^{6}$

Among the solid tumors that can cause FUO, the main ones are the Wilms' tumor (malignant renal tumor, more common in children), neuroblastoma (extracranial solid tumor, more common during childhood), and atrial myxomas (most common primary cardiac neoplasm).Abdominal masses, hematuria, prolonged fever, hypertension, polycythemia, besides a positive naproxen test can suggest a Wilms' tumor.Abdominal, thoracic, or cervical nodules with prolonged fever are suggestive of neuroblastoma. Murmurs intensified with dynamic auscultation maneuvers, with a history of decubitus dyspnea, and presence of a mobile mass on the echocardiography are suggestive of left atrial myxoma. ${ }^{6}$

Auto-inflammatory syndromes caused by genetic disorders (familial Mediterranean fever, mevalonate kinase deficiency, familial Hibernian fever) are less frequent but must be remembered, particularly when the FUO is classified as idiopathic. ${ }^{6}$ Some classes of medications may cause FUO, and its use 


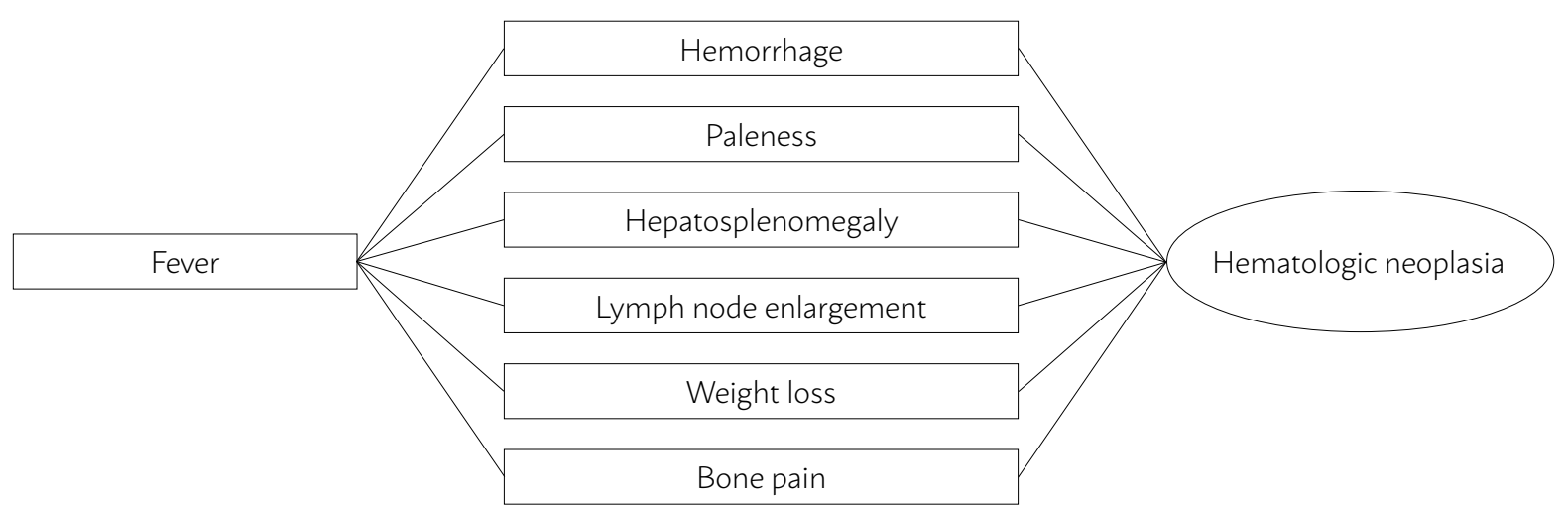

should always be investigated when obtaining the clinical history of the patient. The main classes are antibiotics, anticonvulsants, antiarrhythmic drugs, vasodilators, antihistamines, antileukotrienes, and non-steroidal anti-inflammatory drugs. ${ }^{6.11}$ Sickle cell disease, inflammatory bowel disease, dermatological diseases (e.g., erythema nodosum), thyroid diseases are potential causes of FUO and should also be remembered during the clinical examination. ${ }^{6}$

Between 10-30\% of FUO cases in children remain without a diagnosis. In most of these, the fever stops spontaneously without major complications. The FUO prognosis in children depends on the underlying etiology and early diagnosis, but it is better than in adults. ${ }^{6.11}$

\section{FUO IN ELDERLY PATIENTS}

Few FUO studies focus on elderly patients. These patients often do not have a fever in the presence of an infection; however, when present, the fever may suggest a serious illness. The main FUO etiologies of in elderly patients are infectious (up to $35 \%$ of the cases), rheumatic (up to $30 \%$ of the cases), and neoplastic (up to $20 \%$ of the cases). In this group, it is worth mentioning the most common rheumatic diseases: temporal arteritis, polymyalgia rheumatic, granulomatosis with polyangiitis, polyarteritis nodosa, rheumatoid arthritis, and sarcoidosis. Intravascular lymphoma with uterine involvement has been described as a cause of FUO in elderly women.

\section{NOSOCOMIAL FUO}

The definition of nosocomial FUO requires that patients are hospitalized, with fever $\geq 37.8^{\circ} \mathrm{C}$ on several occasions, in the absence of an infection or disease incubated at admission, and with no diagnosis after three days in spite of adequate investigation (including at least 48 hours of microbiological culture). ${ }^{2}$ Two important causes of nosocomial FUO are pseudomembranous colitis and drug-induced fever. ${ }^{2}$

\section{RESUMO}

Febre de origem indeterminada (FOI) é uma entidade desafiadora com presença marcante nos hospitais de todo o mundo. É definida como temperatura $\geq 37,8^{\circ} \mathrm{C}$ em várias ocasiões, com duração $\geq 3$ semanas, na ausência de diagnóstico após três dias de investigação hospitalar ou três consultas ambulatoriais. As principais etiologias são de ordem infecciosa, neoplásica e doenças inflamatórias não infecciosas. O diagnóstico é baseado na história clínica e no exame físico minuciosos desses pacientes, com a finalidade de direcionar os exames complementares específicos a serem realizados em cada caso. A abordagem diagnóstica inicial do paciente com FOI deve incluir exames complementares inespecíficos. A terapia empírica não é recomendada (com poucas exceções) em pacientes com febre prolongada, uma vez que ela pode camuflar e retardar o diagnóstico e a conduta para tratar a etiologia específica. O prognóstico engloba uma mortalidade de $12-35 \%$, variando de acordo com a etiologia de base.

PALAVRAS-ChaVe: Febre de causa desconhecida. Febre. Criança. Neutropenia. Idoso. HIV. 


\section{REFERENCES}

1. Unger M, Karanikas G, Kerschbaumer A, Winkler S, Aletaha D. Fever of unknown origin (FUO) revised. Wien Klin Wochenschr. 2016;128(21-22):796-801.

2. Lambertucci JR, Ávila RE, Voieta I. Febre de origem indeterminada em adultos. Rev Soc Bras Med Trop. 2005;38(6):507-13.

3. Lambertucci JR, Rayes AAM, Nunes F, Landazuri-Palacios JE, Nobre V. Fever of undetermined origin in patients with the acquired immunodeficiency syndrome in Brazil: report on 55 cases. Rev Inst Med Trop S Paulo. 1999; 41(1):27-32.

4. Rigante $D$, Esposito S. A roadmap for fever of unknown origin in children. Int J Immunopathol Pharmacol. 2013;26(2):315-26.

5. Mekitarian Filho E, Carvalho WB. Current management of occult bacteremia in infants. J Pediatr (Rio J). 2015;91(6 Suppl 1):S61-6.

6. Heinz WJ, Buchheidt D, Christopeit M, von Lilienfeld-Toal M, Cornely OA, Einsele $\mathrm{H}$, et al. Diagnosis and empirical treatment of fever of unknown origin (FUO) in adult neutropenic patients: guidelines of the Infectious Diseases Working Party (AGIHO) of the German Society of Hematology and Medical Oncology (DGHO). Ann Hematol. 2017;96(11):1775-92.

7. Geurts DH, Vos W, Moll HA, Oostenbrink R. Impact analysis of an evidence-based guideline on diagnosis of urinary tract infection in infants and young children with unexplained fever. Eur J Pediatr. 2014;173(4):463-8.

8. Dayal $R$, Agarwal $D$. Fever in children and fever of unknown origin. Indian J Pediatr. 2016;83(1):38-43.

9. Zhou W, Tan X, Li Y, Tan W. Human herpes viruses are associated with classic fever of unknown origin (FUO) in Beijing patients. PLoS One. 2014;9(7):e101619.

10. Beresford RW, Gosbell IB. Pyrexia of unknown origin: causes, investigation and management. Intern Med J. 2016;46(9):1011-6.

11. Kouijzer IJ, Bleeker-Rovers CP, Oyen WJ. FDG-PET in fever of unknown origin. Semin Nucl Med. 2013;43(5):333-9.
12. Revest M, Patrat-Delon S, Devillers A, Tattevin P, Michelet C. Contribution of 18fluoro-deoxyglucose PET/CT for the diagnosis of infectious diseases. Med Mal Infect. 2014;44(6):251-60.

13. Arora R, Mahajan P. Evaluation of child with fever without source: review of literature and update. Pediatr Clin North Am. 2013;60(5):1049-62.

14. Loizidou A, Aoun M, Klastersky J. Fever of unknown origin in cancer patients. Crit Rev Oncol Hematol. 2016;101:125-30

15. Niehues T. The febrile child: diagnosis and treatment. Dtsch Arztebl Int. 2013;110(45):764-73.

16. Cunha BA, Lortholary $O$, Cunha $C B$. Fever of unknown origin: a clinical approach. Am J Med. 2015;128(10):1138.e1.e15.

17. Marshall GS. Prolonged and recurrent fevers in children. J Infect. 2014;68(Suppl 1):S83-93.

18. Mulders-Manders $C M$, Simon A, Bleeker-Rovers CP. Rheumatologic diseases as the cause of fever of unknown origin. Best Pract Res Clin Rheumatol. 2016;30(5):789-801.

19. Vanderschueren $S$, Knockaert $D$. Tackling fever and inflammation of unknown origin: the do's and don'ts. Acta Clin Belg. 2014;69(6):412-7.

20. Bharucha T, Cockbain B, Brown M. Pyrexia of unknown origin in clinical practice. Br J Hosp Med (Lond). 2016;77(10):579-83.

21. Kaya A, Ergul N, Kaya SY, Kilic F, Yilmaz MH, Besirli K, et al. The management and the diagnosis of fever of unknown origin. Expert Rev Anti Infect Ther. 2013;11(8):805-15

22. Hadjadj J, Nielly H, Piekarski E, Cuccuini W, Deau-Fischer B, Hourseau M, et al. Uterine intravascular lymphoma as a cause of fever of unknown origin. Ann Hematol. 2017;96(11):1891-6.

23. Amato Neto V. Febre de origem indeterminada. Rev Soc Bras Med Trop. 1969;|II(6):323-7.

24. Korzeniewski K, Gawel B, Krankowska D, Wasilczuk K. Fever of unknown origin in returning travellers. Int Marit Health. 2015;66(2):77-83. 